\title{
From voting to engaging: Promoting democratic values across an international school network
}

\author{
Rupert Higham $^{1}$ (corresponding author) and Natalie Djohari ${ }^{2}$ \\ 1. London School of Leadership in Learning, UCL Institute of Education, 20 Bedford Way, London
} WC1H OAL

2. Faculty of Education, University of Cambridge, 184 Hills Road CB2 9PQ

Pre-publication version. The Version of Record is available here:

From voting to engaging: promoting democratic values across an international school network

\begin{abstract}
Using a mixed methods design, the researchers investigated understandings and practices of democracy across a worldwide network of 180 schools committed to shared values. An extensive questionnaire received 4020 student and 863 teacher returns; additionally, leaders, students and parents from 5 case study schools on different continents were interviewed. All stakeholder groups were found to value democracy highly, but saw its implementation in their schools as challenging and limited. While staff and parents espoused more holistic understandings of democratic practices and cultures, students focused primarily on systems of election and representation. A framework for developing 'responsible leadership' is offered to deepen students' democratic agency through informed, active and reflective engagement with people, situations and curricula.
\end{abstract}

Keywords: democratic education; values education; responsible leadership; independent schools; democracy; servant leadership 


\section{Introduction}

In considering how to educate for democracy in schools we must recognise that, in many countries, there is a mounting crisis of democratic legitimacy. In established democracies electorates are increasingly divided, antagonistic and distrustful of long-standing politicians and parties; as exemplified by the 'Brexit' vote in the UK, and the victories of Macron over Le Pen in France and of Trump in the US, majority voting often exacerbates rather than relieves these tensions. While democratic structures and procedures remain, the shared culture that supports them is eroding. Meanwhile, the hopes of emerging democracy in North Africa and the Middle East following military interventions and the Arab Spring has foundered, India is facing a crisis of legitimacy in its democratic institutions, and the door to democratisation in China remains firmly shut. The EIU Democracy Index shows no net international progress since 2010 , and that only $4.5 \%$ of the world's population now lives in a fully democratic state, compared to $38 \%$ in outright authoritarian regimes (EIU, n.d.).

Against this backdrop, democratic education faces existential challenges of its own. Are its traditional structures such as student councils legitimate, respected and sufficient? Do they adequately prepare students for participation in increasingly divided societies? We will argue that schools preparing students for politically volatile futures must challenge and support them to become democratically active now. This requires moving away from voting and formal student representation to promoting dialogue around shared and conflicting values at local, national and international levels. In turn, it enables students to put their values into action through informed, reflexive responses to real-world problems.

We start by addressing values education more generally, then education for democracy in particular. John Dewey's philosophy is contrasted with that of Kurt Hahn, and the arising tensions are connected to Derrida's work on the 'paradox of democracy'. We then illustrate 
these tensions in action within a worldwide network of elite schools, inspired by Hahn, in which all members commit to actively promoting democratic values.

\section{Values (in) Education}

Religious organisations rather than nations have historically been the dominant voices in establishing values in schools; this influence remains strong today in many countries (Lovat, Clement, Dally, \& Toomey, 2010). Secular approaches have also gained popularity in recent years: in England, there is the rise of co-operative schools to over 800 ('Co-operative Trust Schools', n.d.); recent classroom-based research on developing character and virtues (Arthur, Kristjánsson, Walker, Sanderse, \& Jones, 2015); and county-wide and international work with the Index for Inclusion (Higham \& Booth, 2016). This growing field is now attracting empirical study - notably Lovat et al.’s (2011) large-scale mixed methodology study in Australian primary schools, which demonstrated cultural change supportive of 'student academic diligence' and 'school ambience', and the relationships and wellbeing of teachers and students where values were embedded (p.13-14).

Many questions remain about which values schools should hold, how they should be embedded (whether transmitted or agreed, for example), and the extent to which they are actually put into practice. Booth sets out a comprehensive response to these questions with a framework of 16 inclusive values in the Index for Inclusion (2011) but stresses that they should not become mere words on a wall:

Values, for me, are only given meaning through action. They are deep-seated beliefs which act as pushes to, or motives for, action - they provide a sense of direction as well as impulses to act in the moment. (2015, pp. 327-8)

Equally important is the field in which values education operates. Is it limited to 'the explicit teaching of values and on connecting values to whole school rules and student behaviour 
management' as in many of the schools in Lovat et al.'s study (2011, p.5), or does it, in the words of Bernard Crick's foundational report on citizenship education in England:

...build on and to extend radically to young people the best in existing traditions of community involvement and public service, and to make them individually confident in finding new forms of involvement and action among themselves. (1998, p. 7)

This outward-facing ambition fits with John Dewey's pragmatist conception of democracy as 'a mode of associated living, a conjoint communicated experience' (1966, pp. 8-9) rather than a topic of study: democratic values are instantiated through humane engagement with others and the world rather than taught.

Crick's focus on service also chimes with the 'democratic forms of cooperation' advocated by Kurt Hahn (James, 1990, p. 7), whose philosophy inspired the creation of Round Square the school network we examine in this article. While Dewey was imagining an ideal society in which education and democracy were continuous and mutually reinforcing, Hahn saw a contemporary world in moral and social decline: in fitness, initiative, imagination, thoroughness, self-discipline and compassion. While younger children were relatively impervious to these forces, the teenage years were a time where cynicism and corruption would follow unless highly motivating alternatives were offered (Hahn, 1998). Drawing on the tradition of 'muscular Christianity' (Millikan, 2013), Hahn's belief in the need for strength of body, will and character profoundly influenced the many schools and youth organisations he founded - including Salem (1919) in Germany and Gordonstoun (1939) in Scotland, Outward Bound (est. 1941), the Duke of Edinburgh Award (est. 1956) and the United World Colleges (est. 1962). Hahn sought to provide what William James called 'the moral equivalent of war' (1995) through demanding programmes of community service that would develop resilience and compassion in young people seeking to prove themselves in the 
world. Young people would be forged through adversity to 'make more of their lives than they thought they could, and learn to serve others with their strength' (James 1990:12). We will investigate below whether these values of 'servant leadership', which are prevalent within Round Square's culture, are compatible with democratic citizenship.

\section{Democracy as 'responsible leadership' through dialogue}

The political climate is not the only challenge to democratic cultures and structures. Derrida (2005) recognised democracy as a fundamentally paradoxical concept: it requires that a state or organisation identifies, counts and equates its subjects in order to represent them - yet must at the same time recognise and value their uniqueness and right to disagree.

Democracy is the only system, the only constitutional paradigm, in which, in principle, one has or assumes the right to criticize everything publicly, including the idea of democracy, its concept, its history, and its name. (Derrida, 2005, p. 87)

Thus in times of insurgency and threat the democratic organisation is forced to suspend some freedoms to speak and act - protecting and undermining itself at the same time. Rather than identify democracy as a state system, then, Derrida aligns more with Dewey in seeing it as a process: of "militant and interminable political critique" (ibid. p. 86) that deconstructs present practices in favour of newly agreed ones. Democracy can never exist fully in the here-andnow as it would become inflexible; instead he talks of "the democracy to come" which "...must have the structure of a promise - and thus the memory of that which carries the future, the to-come, here and now" (ibid, p.85-6, italics in original). This is an ongoing state of responsive intervention in the world in pursuit of its own ideal - thereby holding its contradictions at bay.

The implication of this for schools is that they cannot be democratic simply by having a fixed system of rules and procedures; this would mean telling students in advance what democracy 
looks like without empowering them create it for themselves. We therefore suggest that both Derrida's challenge to democracy, and Dewey's and Hahn's visions of it, demand a focus on promoting the agency of students and teachers (Frost, 2006; Higham, 2016). Biesta argues that our unique selves are not pre-existent or determined, but that our ethical (receptive and non-violent) engagement with others' different perspectives enables our 'coming into the world' (2006, p. 160). This is compatible with a dialogic understanding of identity, whereby the act of making things meaningful is necessarily a response to the gap (or 'dialogic space') we perceive between our perspective and that of another (Wegerif, 2011). By creating environments in which students can respond to difference in accordance with their values, they come to better understand their own, those they share with others, and where they differ (Higham \& Booth, 2016). Thus understood, agency is a form of 'responsible leadership' based on reflection and influence rather than the use of power: it is 'not about people doing what they want do to, but about doing what's there to be done' (Higham, Freathy, and Wegerif 2010, 422. Italics in original).

Central to developing responsible leadership is the disposition of 'openness': 'a readiness and willingness to engage in a genuinely open dialogue with difference and... step outside of previously held attitudes and beliefs in search of deeper understanding' (Higham, 2012, p. 75). This resembles the conception of 'open-mindedness' now held by many ethical theorists in education as a cardinal intellectual virtue (Kotzee 2017, in press), but with a greater emphasis on, in Dewey's phrase, 'active trying and passive undergoing' (1916/1966, p139. Italics in original) than on a quality of abstract thought. Drawing on this work and our evidence, we will argue that students' exercise of genuine agency can bridge the democratic deficit between 'servant leadership' and 'responsible leadership'.

Squaring the circle: can a global network of elite schools share democratic values? 
Round Square, established in 1967 to put Kurt Hahn's philosophy into practice, now incorporates 180 schools spanning 50 countries. To be a member, schools must demonstrate that they actively promote six 'IDEALS' (internationalism, democracy, environmentalism, adventure, leadership and service), and commit to achieving these together through holistic, experience-rich education. The network facilitates this across diverse regions by organising international service projects and expeditions, international and regional conferences hosted by member schools, and staff/student exchange schemes.

From November 2015 to May 2016 we were funded by Round Square to investigate how these IDEALS were understood and implemented by teachers, students and parents across the network. We produced an extensive internal report that highlighted trends, similarities and differences in those understandings. In addition to highlighting substantial good practice, it included recommendations for improvement - notably in relation to impoverished understandings of democracy - on which Round Square has already taken substantive action. We were also given the freedom to use this data to pursue our wider academic interest in democratic, values-led education, of which this article is the result.

Schools in the network are typically fee-paying and prestigious in their respective countries, attracting a high proportion of children from elite families. They are committed both to the IDEALS and to the highest levels of academic attainment. Round Square's recognition of the privilege of its students shapes its strategy:

Because of the nature of the schools and students we are dealing with, in the main talking about people who are going to go on to have fairly senior leadership positions, or a lot of them are going to inherit money or family business or something like that. If we can instil in them an idea of philanthropy at a young age, and the sense of servant leadership and of environmental stewardship and all of those kinds of positive attitudes and behaviours, when they become influential adults they will put all of those behaviours into practice, and influence all of those around them. (Trustee). 
Hahn recognised the tensions in such accounts; pragmatically, he believed that independent schools had greater freedom to pioneer values-led education in a way that would inspire wider adoption, leading to a more compassionate and moral world through an 'aristocracy of service' (Hahn in van Oord, 2010, p. 258). However, this is dangerously close to Thomas Arnold's notion of the 'moral aristocracy', emerging from his Rugby School in England that, as Kenway and Fahey point out (2015, p. 100), implies the inherent moral superiority of the privileged. They strongly critique of the culture of service in elite schools generally, and in Round Square in particular. They present evidence of students' moral and cultural naivety in relation to their acts of charity and support, pointing out how such activities benefit them by building their CVs and international networks with similar students and wealthy charitable patrons. Our findings partially support this analysis, but paint a richer, more varied and nuanced picture from the inside: from accounts of students' naïve 'feel good' giving, to their recognition of the paradoxes of serving others, to their long-term commitments to action for social justice. Rather than engage further in sociological critique, then, we have taken a philosophical approach, exploring Round Square stakeholders' uses of the term 'servant leader'. Despite its inherent paternalism, might it still 'accelerate developments by example' (Hahn in van Oord, 2010, p. 258) towards more democratic engagement in an unequal system where Round Square graduates, who are as much the products of their circumstances as those in poverty, already stand a much greater chance of attaining positions of influence (Green, Henseke, \& Vignoles, 2017)?

\section{Methodology}

Our original research was driven by three questions:

1. How are the six IDEALS understood by staff and students across the network?

2. How are they valued? 
3. How widely are they implemented in school practice?

These allowed us to identify and interrogate discrepancies between each of the IDEALS as a shared aspiration and as lived experience in schools. A mixed method approach captured descriptive statistical data across the breadth of the network on teachers' and students' value rankings of the IDEALS and the extent of their implementation (questions $2 \& 3$ ), and qualitative data exploring how the IDEALS were interpreted, valued and articulated by staff, students and parents (questions 1\&2).

Our design consisted of three elements. First, a self-administered, voluntary online survey for staff and students was distributed across 150 schools. Schools with less than a year's membership or whose status was under review were excluded. We received 4883 complete survey responses of which teachers $17.7 \%$ (863) and 82.3\% (4020) were students aged 11-18. Responses came from 73 schools, $58.1 \%$ of which were from 20 schools in South Asia. The survey, detailed in Table 1, gathered data on implementation through a bank of indicator statements assessed through 5 point Likert scale, and a choice of 'best fit' statements, to identify any dominant IDEALS in the network and any broad differences between student and teacher experiences (question 3). Differences in relative valuation of the IDEALS (identified through forced ranking questions) were also obtained and analysed for regional, gender or age differences (question 2). The survey was piloted to teachers and students regionally before being deployed across the Round Square network.

\section{Insert Table 1 here}

Second, we conducted semi-structured interviews (via skype, 45-60 mins) with 6 Round Square stakeholders: the Chief Executive Officer (CEO), the Chair of the Trustees, and 4 regional Trustees - who were also questioned about their role as heads of schools. 
Third, five schools were chosen as case studies, reflecting Round Square's diversity of regional location (each from different continents), size (from 311 students to 1,840 aged 318) and length of membership (3 to 46 years). All were fee-paying institutions and the main language of teaching was English. Cases were not used as a representative sample for direct comparison with the survey data but served, alongside stakeholder interviews, to explore the ongoing dialogic process through which the IDEALS are understood and valued (Questions 1\&2). At each school, Heads and Round Square representatives were interviewed via skype; three parents were interviewed via email; and two student focus groups were led and recorded by two 16-18-year old students trained by the research team. The peer-led focus groups proved valuable given that we found some contrasts between students and teachers survey responses regarding the value they placed - particularly on democracy. Staff interviews also revealed ideological motivations among teachers to encourage particular IDEALS in students that could have unintentionally influenced focus group discussions if they had been present (Fargas-Malet, McSherry, Larkin, \& Robinson, 2010, p. 184).

Qualitative data was analysed through a combination of theory-led and emergent data-led thematic coding (Boyatzis, 1998) reflecting the broad distinctions between instrumental value, personal development/self-discovery, and valuations orientated to interpersonal development and social awareness, that emerged in staff and student responses.

Heads of schools consented to the participation of their schools as a case study conditional on specific findings and quotes not being attributed to individual schools in publications; thus we have not disclosed their names or exact locations, and have removed other potentially revealing details. All case study schools received a summary report of findings for their school. Fully informed consent was gained from all participants, and included an opening statement in the survey and secondary consent from parents/guardians of all focus group participants. 
The results presented below focus selectively on Round Square stakeholders' understandings and practices around 'democracy' rather than on all of the IDEALS; nonetheless we found that, in interviews and focus groups, democracy was consistently connected to both 'leadership' and 'service'. This is reflected in our analysis.

\section{Findings and discussion}

\section{Questionnaire responses}

Overall, there were remarkably few substantive differences in the ranking of the IDEALS according to gender, region, age or role, or of the level of agreement with the statements that each of them is important both to them personally and to their school. This suggests a strong shared culture based on Round Square's IDEALS and the shared characteristics of its schools (e.g. elite, English language predominant). Where such differences emerged between students and teachers regarding democracy, they are explored below.

Both teachers (21\%) and students (19\%) most frequently ranked democracy second highest in importance among the IDEALS for students to experience at school. However, both most frequently 'agreed' (rather than 'strongly agreed' as was the case with all other IDEALS) that democracy was important to their school. Students frequently (25\%) ranked it last in terms of which of the IDEALS their school does best; teachers (19\%) most frequently ranked it second last (although ranking was more evenly distributed). This suggests that stakeholders set the democracy bar high, but believe that their schools do not yet clear it.

Stakeholders also recognised that student voice and experience of democratic engagement were crucial, but are limited by schools' power structures. In choosing only 3 statements from 9 about the importance of democracy, $44 \%$ of students chose 'learn to speak up about matters that are important to them', and 30\% chose 'learn to value democracy through direct experience'. Most teachers chose the same two statements, but in reverse order of popularity; 
$35 \%$ also chose 'learn to reflect on their values and beliefs' as important for students. The most identified barrier to developing of democracy was: 'there is a limit to how much power students can have in a school' (59\% of teachers, $37 \%$ of students). Students and teachers broadly 'agreed' (mode=2) that students are consulted and have influence. However, they also 'agreed' that students should be better represented on decision-making committees; furthermore, students on average took a neutral position on the statement: 'the most popular students win student elections even if they are not the best for the job', suggesting differing opinions, while teachers on average leaned towards 'disagree'. Taken together, these statements reveal another tension: that if democracy is understood as primarily relating to internal school matters, then it is likely to divide teachers and students, and students from their peers, rather than unite them in pursuit of wider goals in the outside world.

\section{Insert Figure 1 here}

Students' and teachers' reasons diverged most over 'reflect on their values and beliefs' and 'become more aware of the experiences of others', which suggests an emphasis from teachers on students' moral development and the need for empathy mirrored across other parts of the questionnaire - particularly in relation to 'service' - while students remain more focused on developing their character, skills and prospects.

\section{Insert Figure 2 here}

The alignment of staff and students' opinions on how well democracy is implemented within school practice is remarkable, suggesting similar perceptions. Overall, then, the questionnaire responses suggest that democracy is valued as important, but problematic and less fully implemented than the other IDEALS. Several of the highlighted issues were explored further through the interviews and focus groups reported below.

\section{Interviews and focus groups}




\section{Lack of a clear definition of democracy}

The essential difficulty of understanding democracy in theory and practice was illustrated several times in student focus group discussions:

I don't think we're really taught about democracy to be honest. Looking at that word I just think 'what's that'? Obviously I know what it is but I don't know whereabouts in school we have that. I know we all have a say, but.... (student)

This student's struggle to define democracy is representative of widespread divergence and confusion. While students' conceptions tended to be procedural, linked to representation and voting, staff tended to think of democracy in more abstract terms:

You can expose students to adventure activities, and you can actually touch and feel what they are. I'm not sure you can do the same with democracy, which is an ideal, which is a state of mind. (staff)

While both perspectives have merit, neither is sufficient. Democracy is a state of mind in that it requires a shared culture of genuinely caring about, and looking to learn from, the positions of others and a commitment to engage across the differences between them. However, it takes concrete forms including the establishing of principles and decision-making procedures.

Other students struggled in their focus groups to flesh out these concepts:

Leader: Any ideas how we can incorporate democracy more into the school?

Student 3: Maybe link lessons we have to life skills - we could put more into that.

Student 2: Maybe the students could make more of an input into decisions?

Student 3: Maybe we could have some people come to talk to us about it bit more from their point of view?

Fragments of democratic practices are revealed here through discussion, with an implicit recognition that their understanding is partial; it requires clearer framing with agreement on 
principles to become coherent and powerful. For one teacher, this must be achieved through further integration into everyday teaching: 'Our weakest pillar is democracy and that's why we need to be writing it into our curriculum'. Democracy is not an intuitive concept, nor are there many outstanding models of its practice at school or societal level on which schools can readily draw. Yet, given that most Round Square schools committed to its IDEALS and are located in nominally democratic countries, it might be embarrassing for staff or students to profess a lack of understanding. This must be overcome through encouraging continued dialogue across difference - precisely what Student 3 requests above.

\section{Voting, elected roles and student voice}

Many students identified voting as the key feature of democracy, usually regarding elected student roles. Such practices were widespread and valued:

I feel democracy is a system where those in power give some of that power to those beneath them... the school allows us opportunities to exercise democracy when we are selecting head prefects or leaders of an extracurricular activity. I feel that we are all given the chance to voice our opinions. (student)

While this student feels that representative democracy enables students' voices to be heard, this metaphor suggests that power is understood as handed down to students by staff, rather than generated from the rights and voices of the students themselves. The tensions around this were explored honestly by one staff member:

What we have struggled with is the election of our head boy and head girl. It was democratic, and then it became a popularity vote - we didn't quite get that right. So we've moved away from that for the past four years. We listen to what people say, but it's not an objective criteria which is pure democracy. Because some of the quiet ones, 
the introverts, weren't really getting a good show - and they were the best leaders for me. (Head)

The description of elections as 'popularity contests' arose a few times during interviews, as it did in parents' proud references to their children's appointments. However, the focus on developing individuals' leadership skills, seen as so valuable for the future, is in tension with collective democratic representation:

For me it is completely relevant that we have democracy and leadership right alongside each other because leadership is a part of democracy, the fact that people take roles of leaders, and they are elected in a democratic way, it shows the process in which the school takes part and involves students. (student)

This student saw participation in elections as a powerful life experience in its own right, giving valuable opportunities to develop leadership skills. In contrast to the teacher above, he suggests that selection of leaders by voting alone is sufficient and valid. However, other students were less satisfied with a conception of democracy focused on voting, for example: 'They have democracy because I voted for the Head, and that was probably it'. Several who defined democracy in this way expressed a sense of its limitation or even tokenism:

Student 4: I put democracy because we choose our captains. Yes, we don't directly get exactly what we want but it is an election that leads to a selection by everybody. Student 3: So you feel that the mere virtue of us getting a voice is enough for democracy?

Student 4: Yes, for me.

Student 3's wry question expresses cynicism about voting for captains as representing genuine student voice. Other students, however, understood the opportunity to speak one's 
mind, being heard and considered respectfully, and learning from others, as the essence of democracy in school:

Student 7: I don’t agree with democracy being [ranked] last because our school encourages it in some parts, for example freedom of thought, accepting others' opinions - it's exactly what we are doing right now, it's just talking, listening to their opinions, and understanding.

Yet the inherent limitations of this perspective emerged from another discussion:

Focus group leader: Which IDEALS are harder to achieve?

All students: Democracy.

Student 3: I think democracy, because everyone wants to speak, no one wants to listen. And so should you respect my rights when nobody really thinks they should respect yours?

This student also recognises a limitation to the concept of 'student voice': that expressing opinions is valueless if nobody is really listening. Neither the opportunity to express opinions, nor to vote for representatives, itself develops the culture in which genuine listening prevails: one of openness and responsiveness that go well beyond turn-taking. The structures of democracy can only flourish in a climate of equity and widening collective responsibility.

\section{Participation and responsibility}

Teachers and parents gave richer, more multifaceted accounts of democracy than students:

In my mind, the ideal of democracy is students being part of the decision and change making processes within the school. And that means more than deciding what we are selling in the canteen - it has to do with school philosophy and what we value in the school. I don't think it's necessary for it to be a voting process - having a culture of valuing student opinion is the critical thing for me. (staff) 
This teacher sees democracy as a collective process of action, rather than as a choice of options, that should operate directly among all members not through elected representatives. Some students saw scope for this richer form of democratic engagement:

Democracy is also about giving people the power, and we are given so much faith and opportunity just to develop projects, or just like Student 2 was saying, in our House competitions, where people actually have the power to decide what's going to be done and how it's developed. (student)

This student's sense of empowerment and enthusiasm for being given the opportunity to lead with others is palpable, even at a modest level of responsibility. One Head recalls how another Round Square school took student involvement in decision-making further:

A Head from our region told us that he has students on the school management committee, which was a totally new idea for me. I, coming from a very traditional school, would not for the life of me even think that they could - and they sit them in on the selection of teachers! (Head)

This sense of incredulity at genuine student involvement in responsible decision-making was shared by a student also:

I think students cannot participate in major decisions about school - we probably don't know many things that the parents or the student council know. So that's why I think there are some things we could vote in but not making buildings and things like that. (student)

Again, this suggests variability in beliefs around the students' possible remit and an underestimation of their capacities. Why would students be thought incapable of contributing to a process of teacher selection or building specification? Such hesitancy suggests that, even for some schools with democracy as a core value, significant student responsibility is an 
exotic notion; engagement with other Round Square members, however, can provide valuable challenge and resources in this regard.

More broadly, the notion of democracy as a set of rights and responsibilities was another recurring perspective among staff and parents, underpinned by a sense of societal benefit:

Slowly, over the years, our students have understood that democracy is an understanding of not only of your rights, but an understanding of your responsibilities.... And that's the kind of spirit that we are inculcating our students with when they go out, that they're not just thinking only of themselves. They're thinking about the collective good. (staff)

Many students did indeed focus on rights: 'Democracy is when we have the right to choose our leaders, we have the right to vote'. This positive assertion is welcome in contrast to earlier student definition in which such rights are seen as conferred by adults. However, parents and staff were more likely to say that democracy is also crucially about accepting responsibility for others:

In this country we grew up hearing that democracy is a state of government, and we try to invite that in the functioning of our school....However, as we came along, we met with other people and exchanged ideas and realised, no, democracy also means respect, it means responsibility, and it means knowing what your rights are. (staff)

This portrays democracy as about the quality of interactions between people and the spirit in which they are undertaken; the staff member's developing understanding of democracy in the light of cross-network engagement is a case in point. Overall, the gulf in understanding between adults and students about the role of participation in democracy was clear - we will return later to how it might be addressed. 
Another factor in staff's definitions and discussions of democracy in their schools was the wider political and cultural contexts in which they live:

Years ago there was a totalitarian dictatorship here, and there is now a fairly well established democracy, with a relative degree of freedom in the press. Whereas when I first came here if you mention the president's name in a restaurant you could be arrested. Those children have grown up with a very rapid process of democracy unfolding around them. So, engaging students in an awareness of how that process unfolds is crucial. (Head)

This Head suggests that living in a country going through a rapid process of democratisation inflects a different character on internal school democracy - students are more likely to recognise its overtly political nature. However, another Head suggested that in nondemocratic states the value can be a refuge:

The fact that students might live in a politically non-democratic country is irrelevant in my view to them as individuals. So that the first reason why I think the democracy pillar is a challenge is that people struggle to move away from democracy as we refer to it on a daily basis in terms of political systems. (Head)

This Head asserts the right to consider democracy less procedurally and more as a principle to be recreated within the school community - while recognising the difficulty of breaking our habits of thinking. A common assertion emerges from the quotations above: that democracy is primarily about engaging with others and within (or against) the local context. This echoes Hahn's insistence on the necessity of service to the local community in his schools - a tradition that continues in Gordonstoun School, whose 'twelve services' include volunteer fire, coastguard and mountain rescue, all run and operated by the students. We will now explore this as a bridge to moving beyond procedural conceptions of democracy. 


\section{Servant Leadership}

Earlier we argued that democracy can be more powerfully understood as putting humane equitable values into action beyond the walls of the school, locally and internationally. Round Square schools can offer powerful and supportive environments for this:

The cake sales and the fundraising isn't really what it's all about. What it's really all about is when one of my kids goes to Costa Rica, or one has just come back from Vietnam, and it's changed his life. He's had to raise the money himself because he's been part of a project - it was to do with homeless women and building a centre - so that's a servant leader. If he can bring that back into his career then he will become humble. (staff)

This teacher suggests that while local charitable activity may have its place, the transformation in terms of a sense of duty and humility comes through the face-to-face encounter with those in poverty, and working to improve their lives. Servant leadership is suggested to be a form of voluntary self-abasement, acknowledging and putting aside one's privileged status and doing humble work on behalf of others. This is seen as particularly important due to their likely future positions:

Our students come from very privileged backgrounds... So I was looking for something that would actively address the preparation of some of these young people for leadership roles, to ensure that they didn't turn out like their parent's generation for whom leadership means demonstrating your ability to be powerful over others usually by keeping the other subjugated and amassing wealth and privilege around yourself.... Round Square seemed a great opportunity to address philosophically and in practice that concern about preparing students for a genuine servant leadership approach. (Head) 
Round Square teachers work under the assumption that their student will be leaders, and that it is thus up to them to shape them as particular sorts of leader - an assumption shared by some students also:

You could argue that service is less prominent than leadership because service needs to be reinforced by certain teachers and certain activities, whereas leadership is an integrated part of everyday life. We don't have to think about it. (student)

This student recognises that leadership is assumed within the Round Square environment, whereas the concept of serving others 'needs to be reinforced' by teachers and activities. This raises a key dilemma: stating the importance of leadership inevitably sends a different message in a school with a privileged student population than it does in a mixed or underprivileged school. In combination with the implicit messages given from wider society about the inherent superiority and deservingness of those in elite positions, the risk of promoting arrogance or entitlement is great - hence the very strong focus on humility and duty from teachers and some parents: 'Our daughters are appreciating that a true leader has to be a servant and this value is embedded in the school's culture'. Furthermore, told several stories given of some students' extraordinary efforts to take a lead on their own initiative to help those less privileged:

My younger daughter imbibed the spirit of service from the students of United World Councils Singapore. She has proposed a plan on how to involve the kids of all agegroups in community service in school. She believes kids should learn at an early age to give back to society. (parent)

There were several remarkable stories of students inspired to take sustained action to help others following such experiences. However, these comments also contain a strong sense of realpolitik: these students will be leaders anyway, so investing in them particularly - with 
resources and opportunities unavailable to others - is worthwhile for the sake of the many others who will come under their influence. It is an ethical compromise, recognising entrenched economic and social inequality and designed to sow the seeds for a less unequal future. One path towards the resolution of this dilemma is suggested, however, in this parent's comments: that leadership can be demonstrated not (just) as service to others, often in the form of philanthropic activity or sharing the wealth, but as empowering others - or seeking to tackle the systems that perpetuate inequality of wealth and influence in the first place.

Students did not frame their discussion of leadership and service in these terms, but there was evidence from some that the exhortations towards humility were influencing them: 'I think that everybody can be a leader because everyone can speak out and they can help others'. This is an inclusive and outward-looking sentiment that suggests how servant leadership might, through dialogue and practical opportunity, move towards democratic citizenship locally and globally.

\section{Conclusion}

Even the most privileged teenagers might not feel so in an immediate sense; the culture and institutions they inhabit restrict personal freedoms and put great pressure on them to outperform others, while expecting them to develop their character, discover their path in life and achieve social and economic success. Unlike the anxieties that these pressures cause, the demographic indices of their likely longevity, future wealth and capacity to make choices remain abstract to them. Round Square schools' moral and social expectations ask yet more of their students; it is small wonder they ranked leadership as more important to them than service, as the former suggests a path of personal development towards those expected outcomes. It is unsurprising that, concerning democracy, fewer chose 'becoming more aware 
of the lives of others' than 'learning to speak up about matters important to them' and 'learning about democracy through direct experience': their characters, values and identities are in formation, making it harder to understand others and more urgent to discover and prove themselves.

In this situation, Hahn's conception of servant leadership is a stern tonic: it demands pushing children to the edges of their endurance to discover that the medicinal tang of serving others fulfils them more than the saccharine rush of hedonistic pleasure. Not all will live up to this expectation, especially within a cultural climate where that message is contradicted, and they risk being branded as moral failures by themselves and others as a result. Servant leadership also requires resources and opportunities - even if Round Square students could become an inspiring 'aristocracy of service', others would not have the means or opportunity to follow suit. More damagingly, servant leadership here places the power of decision-making in the hands of the privileged - who set the terms of their service rather than negotiating them with those they wish to serve. It can thus become institutionalised and tamed through bounded charitable activity, '(re)constituting normative inequality' through 'a process of 'decontestation' that blocks out significant critiques of structural inequality by focusing on surface-level, localised amelioration of need (Sriprakash, Qi, \& Singh, 2016, p. 1). Running a volunteer flood response service, for example, might seem uncontentious in responding to need; however, it may not address the issues of poor quality housing, socio-economic isolation and global climate change that cause the symptoms it ameliorates. What it will certainly provide, as Kenway and Fahey (2015) argue, is life experiences for the volunteers that are of intrinsic and extrinsic value, further distinguishing them from their poorer peers. Our evidence demonstrates a substantial gap in sophistication between Round Square students' and adults' conceptions of how schools should engage with democracy. Many teachers and parents are seeking to move students beyond procedural understandings: service 
beyond static charitable activities; leadership beyond developing personal characteristics valued in the marketplace; democracy beyond voting, representation and power sharing. Those who spoke to us were calling for developing dispositions that support a humane, diverse, and global vision of democratic societies rather than the nationalistic visions currently in the ascendancy. We argue that this accords with the pattern of developing the skills, habits, dispositions and democratic agency required for 'responsible leadership'. The quality of student discussions exploring democracy and some of the powerful stories that emerged from interviews suggest that such development is possible, albeit in the face of strong pressures to focus on personal advancement relative to others. By encouraging students first to seek out, value and learn from the different perspectives and situations of others, and then to be responsive to their desires and needs, schools can help students to become, in Crick's phrases above, 'confident in finding new forms of involvement and action among themselves' as well as learning from and extending 'the best in existing traditions of community involvement and public service'. Rather than taking a lead through static forms of charitable service, students should be encouraged to critically engage with the wider issues that underpin others' needs. By doing so they would be serving, in Derrida's terms, 'the democracy to come'.

But how might this practically be achieved? First, the powerful experiences that can open Round Square students' horizons must be linked to deeper knowledge of context, and to further opportunities for reflection and agency. This requires deeper integration into school life - including into the curriculum - if the forms of isolated engagement with democracy and service discussed above are to be avoided. The Index for Inclusion offers a model for integrating course content with democratic action. It reframes traditional disciplines within 13 new subjects that all focus on vital areas of shared life that are of relevance to all such as: food; energy; health and relationships; the Earth, solar system and the universe; and ethics, 
power and government (Booth \& Ainscow, 2016, p. 13). Each of these subjects explicitly links local to global, past to present and future, and presents opportunities for a range of disciplinary perspectives. By presenting a range of questions to stimulate curiosity and exploration rather than lists of fixed content (for example, "Do children learn about food through school meals and use of the cafeteria?"; "Do children consider the way poverty and wealth can both lead to the lack of the conservation of finite resources?"), they encourage student agency and valuing difference. By explicitly situating students within dilemmas and complexity, they seek to foster democratic participation based on 'active trying and passive undergoing'. Here Dewey's theory of learning serves to highlight a limitation in Hahn's: experience arises through reflecting on the value of our sensations in relation to one's 'end in view' (Dewey, 2016, p.146). Thus just serving others in a prescribed fashion - however worthy and rigorous - is not enough to develop democratic agency. Only by learning about, engaging with and reflecting on what has been, what is and what ought to be can students 'come into the world' as democratic agents in increasingly uncertain times.

\section{References}

Arthur, J., Kristjánsson, K., Walker, D., Sanderse, W., \& Jones, C. (2015). Character education in UK schools: Research report.

Biesta, G. (2006). Beyond learning: Democratic education for a human future. Boulder, CO: Paradigm Publishers.

Booth, T. (2015). Is 'Learning without Limits' a Framework of Values? FORUM, 57(3), 325.

Booth, T., \& Ainscow, M. (2011). Index for Inclusion: developing learning and participation in schools. Bristol: CSIE.

Booth, T., \& Ainscow, M. (2016). Index for inclusion: a guide to school development led by inclusive values (4th Edition). Cambridge, UK: Index for Inclusion. 
Boyatzis, R. (1998). Transforming qualitative information: Thematic analysis and code development. London: Sage.

Co-operative Trust Schools. (n.d.). Retrieved 2 February 2017, from https://www.coop.ac.uk/our-work/schools-and-young-people/co-operative-trust-schools/

Crick, B. (1998). Education for Citizenship and the Teaching of Democracy in Schools. London: QCA.

Derrida, J. (2005). Rogues. (M. Naas, Ed.). Stanford, CA: Stanford University Press.

Dewey, J. (1966). Democracy and Education. New York: The Free Press.

EIU Democracy Index 2016. (n.d.). Retrieved 7 July 2017, from https://infographics.economist.com/2017/DemocracyIndex/

Frost, D. (2006). The Concept of 'Agency' in Leadership for Learning. Leading and Managing, 12(2), 19-28.

Green, F., Henseke, G., \& Vignoles, A. (2017). Private schooling and labour market outcomes. British Educational Research Journal, 43(1), 7-28.

Hahn, K. (1998). Erziehung und die Krise der Demokratie. In M. Knoll (Ed.), Reform mit Augenmaß: ausgewählte Schriften eines Politikers und Pädagogen. Stuttgart: KlettCotta.

Higham, R. (2012). Developing pedagogy for responsible leadership: Towards a dialogic theory of democratic education. University of Exeter, Exeter.

Higham, R. (2016). Communication breakdown: How conflict can promote responsible leadership in students. School Leadership \& Management, 36(1), 96-112.

Higham, R., \& Booth, T. (2016). Reinterpreting the authority of Heads: Making space for values-led school improvement with the Index for Inclusion. Educational Management Administration \& Leadership, 1741143216659294. 
James, T. (1990). Kurt Hahn and the aims of education. Journal of Experiential Education, 13(1), 6-13.

James, W. (1995). The moral equivalent of war. Peace and Conflict: Journal of Peace Psychology, 1(1), 17-26.

Lovat, T., Clement, N., Dally, K., \& Toomey, R. (2010). Values education as holistic development for all sectors: Researching for effective pedagogy. Oxford Review of Education, 36(6), 713-729.

Lovat, T., Toomey, R., Dally, K., \& Clement, N. (2009). Project to test and measure the impact of values education on student effects and school ambience. Newcastle, Australia.

Millikan, M. (2013). The Muscular Christian Ethos in Post-Second World War American Liberalism: Women in Outward Bound 1962-1975. In J. J. MacAloon (Ed.), Muscular Christianity and the colonial and post-colonial world (pp. 138-155). Routledge.

Neill, A. S., \& Lamb, A. (1995). Summerhill school: A new view of childhood. Macmillan.

Patton, P. (2007). Derrida, Politics and Democracy to Come. Philosophy Compass, 2(6), $766-780$

Sriprakash, A., Qi, J., \& Singh, M. (2016). The uses of equality in an elite school in India: enterprise and merit. British Journal of Sociology of Education, 1-12.

van Oord, L. (2010). Kurt Hahn's moral equivalent of war. Oxford Review of Education, $36(3), 253-265$.

Wegerif, R. (2011). Towards a dialogic theory of how children learn to think. Thinking Skills and Creativity, 6(3), 179-190. 